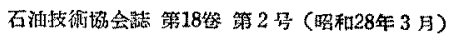 JOURNAT, OL JAPANESE ASSOCIATION OE PETROLEUM TECHNOLOGISTS VOL, 18, NO, 2 (March, 1953) \\ 茂原天然ガス田の相対的滲透率*
}

一相炎的澶透率の研究一

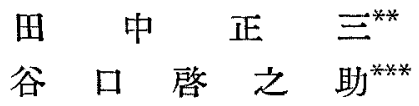

(昭和 27 年 12 月 19 日受理)

\section{On the Study of the Relative Permeability in the Mobara Gas Field}

By

Shozo Tanka, Keinosuke Tanigdohi

\begin{abstract}
The objects of this investigation are the measurements of relative permeability of the sands in Mobara Gas Field and the improvements of the technique and apparatus used on the experiments.

The results obtained from the experiments are given on Fig. 3 and Fig. 4. Fig. 3 shows warer permeabilities in the case of very low value, but the writers have not enough data to explain on the factors affecting on the low values.
\end{abstract}

\section{1. 緒言}

本的究に额いては，千葉舅長生郡茂原天然ガス日のガ

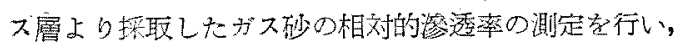

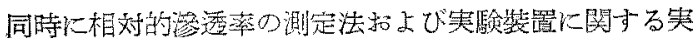

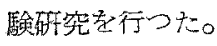

\section{2. 測定裝置およひ測定法}

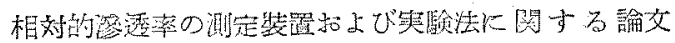

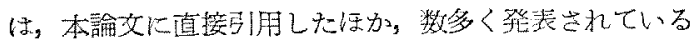

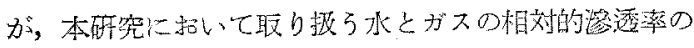

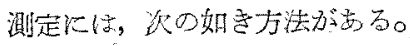

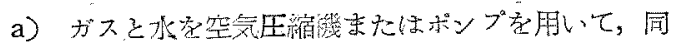

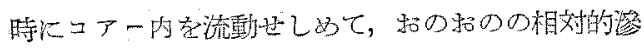

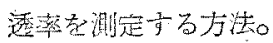

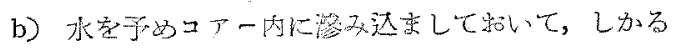

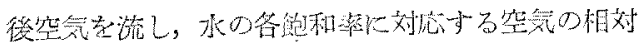

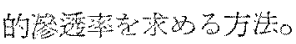

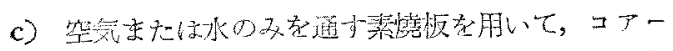

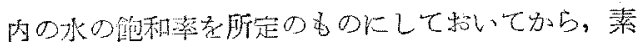

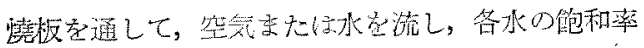

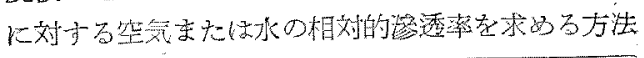

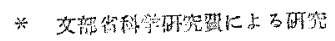

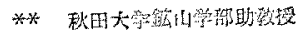

*** 间 $\mathrm{E}$ 期手

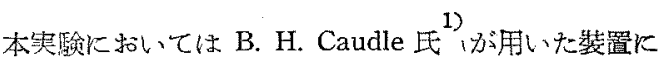

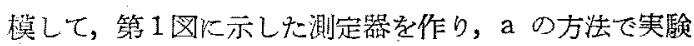

第 1 图 相効的渗透率湘定器

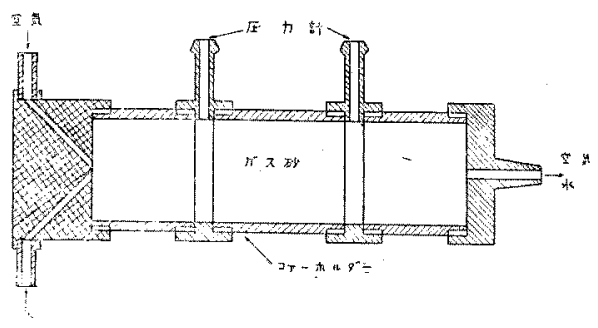

を行了尒定であったが，水在送り达む裝置が不完全であ

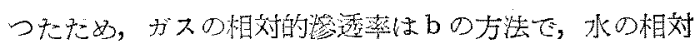

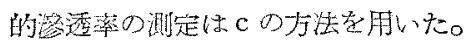

(i) ガスの相對的参透率の測定 測定覺置としては空

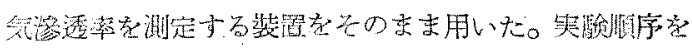
次にのべ。

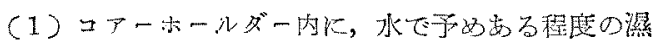

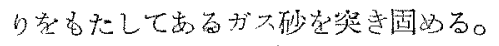

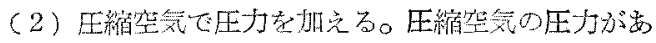

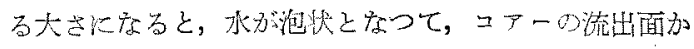

1) B. H. Caudle, R. H. Slobod and E. R. Brownscomble,: Further Developments in the Laboratory Determina. tion of Relative Permeability, Journal of Petroleum Techology, Vol. III, No.5, (May, 1951): 
ら流出し始める。この時の圧縮空気の压力は，コアーの 毛細管压力之も考古られるすので西る。

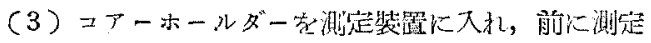

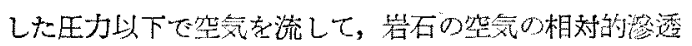
率を測定する。

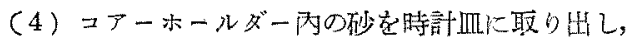

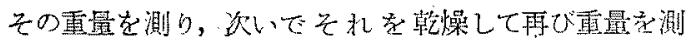

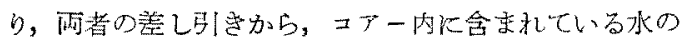

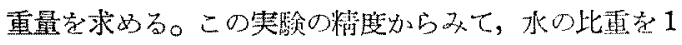
として取り报つた。

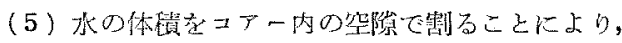

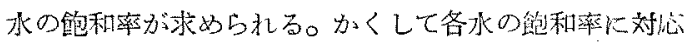

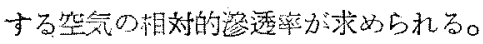

(ii）水の相對的灙透率の測定 第2图に示した测定器

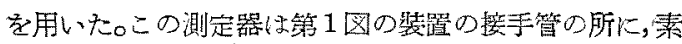
燒板をデコチンスキーセメントで固定したもので岕る。

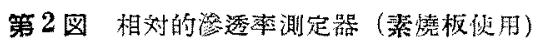

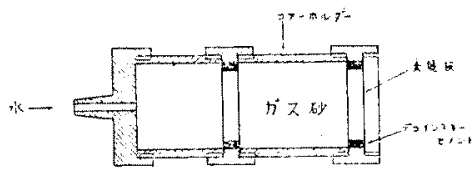

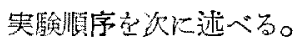

（1）コアーホールダー们に，水で予好缹り老もたし たガス砂を笑き固好。

(2) 測定器を第 2 図の如く組立てる。

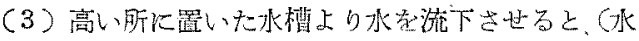

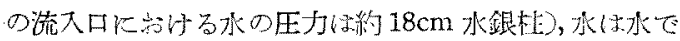

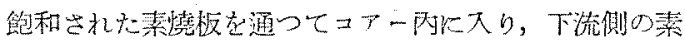

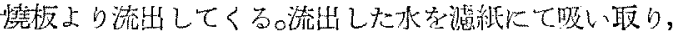

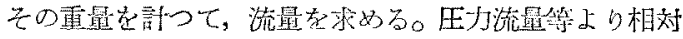

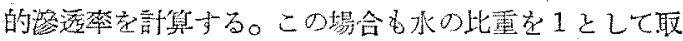

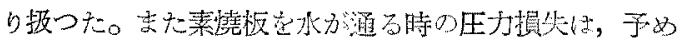
测定して和く。

(4)コアーホールダー5り砂去取り出し，前と同㧼

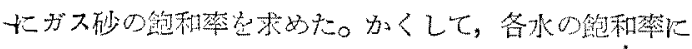

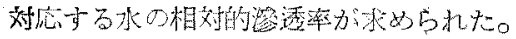

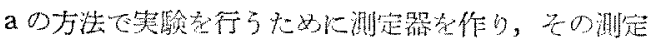

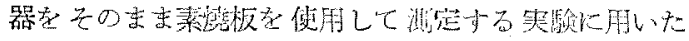

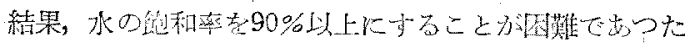

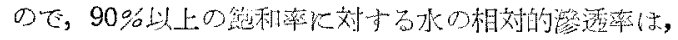
次の如々乙て求好た。

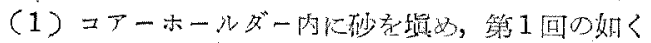

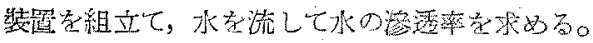

（2）コアーホールダーからガス仯至取り出し，水の 飽和摔求める。
ガス砂の中に保存してする空㑹は，完全飞水により押 し出さ机方こをなく，1部はュア一队留まるから，各 实験ごとに罢つたガスの館和㳯に対する水の相刘的滲透 率が求るるしかしか古る方法では，水の织和率老調節

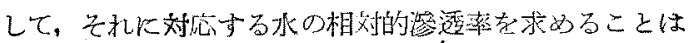
できない。

\section{3. 実 験 凟 料}

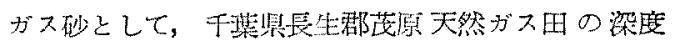
$350 \mathrm{~m} \sim 450 \mathrm{~m}$ ，地凰 $\mathrm{U}_{4} \sim \mathrm{U}_{0}$ より㳟取せるるの在用いた。

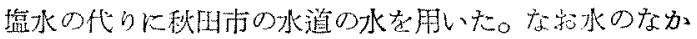
飞溶解している空気は拢き取つてない。天然方不として。 空気を用いた。

\section{4. 実 験 結 果}

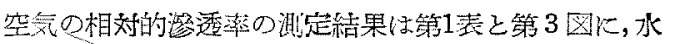

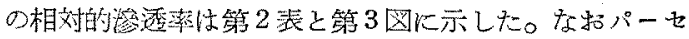

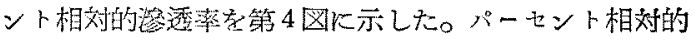

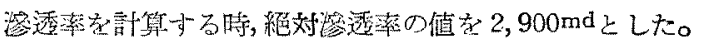

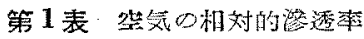

\begin{tabular}{|c|c|c|c|}
\hline 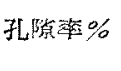 & 的和等\% & 滲透染* $\mathrm{md}$ & 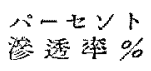 \\
\hline 47.6 & 77.0 & 50 & 1.72 \\
\hline 45.1 & 72.1 & 248 & 8.55 \\
\hline 45.9 & 70.1 & · 451 & 16.00 \\
\hline 44.4 & 64.9 & 581 & 20.00 \\
\hline 42.8 & 61.3 & 791 & 27.30 \\
\hline 44.7 & 56.7 & 950 & 32.80 \\
\hline 46.1 & 56.1 & 1160 & 40.00 \\
\hline 45.3 & 51.8 & 1550 & 53.70 \\
\hline 45.5 & 51.1 & 1690 & 58.40 \\
\hline 45.6 & 46.5 & 2200 & 75.80 \\
\hline 45.2 & 37.2 & 2360 & 81.30 \\
\hline 45.0 & 21.8 & 2690 & 92.80 \\
\hline 46.6 & 12.6 & 2820 & 97.30 \\
\hline$\cdots \cdots$ & 0 & 2900 & 100.00 \\
\hline
\end{tabular}

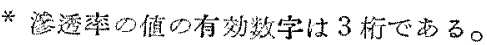

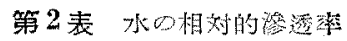

\begin{tabular}{|c|c|c|c|}
\hline 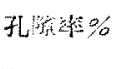 & 能和䇣 \% & 渗䢩軎 md & 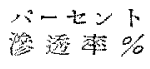 \\
\hline 43.1 & 95.5 & 27.6 & 0.952 \\
\hline 40.8 & 94.8 & 24.8 & 0.852 \\
\hline 41.0 & 93.1 & 19.0 & 0.652 \\
\hline 42.2 & 86.6 & 10.3 & 0.355 \\
\hline 41.4 & 77.2 & 5.85 & 0.202 \\
\hline 42.5 & 70.5 & 4.15 & 0.143 \\
\hline 41.7 & 56.1 & 0.584 & 0.020 \\
\hline
\end{tabular}




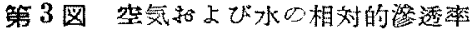

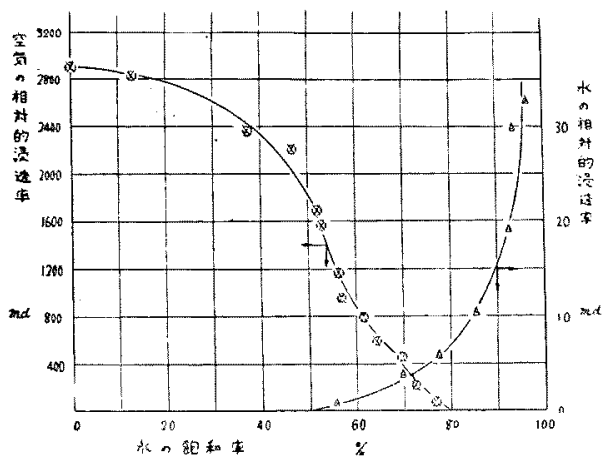

第4图空気和よび水のバー七ント相效的透率

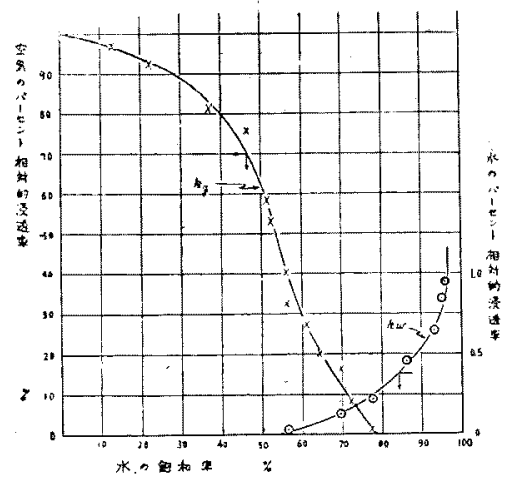

5. 実験 結 の 檢討

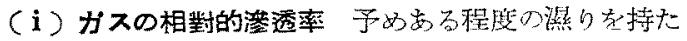

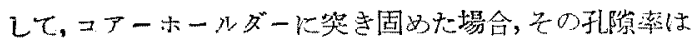

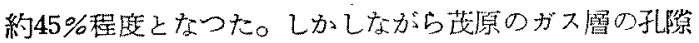
率か，45\%程度でする加否加疑間でする。 Leverett氏2)

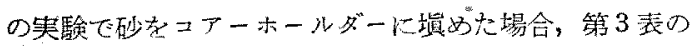
如くなつている。この記鋢考参照するに，本奏駼では，

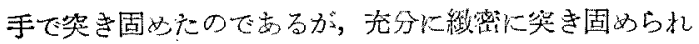
ている考克ら礼る。

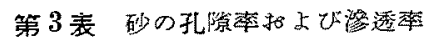

\begin{tabular}{|c|c|c|c|c|c|}
\hline \multirow{2}{*}{$\begin{array}{l}\text { 览の } \\
\text { 番号 }\end{array}$} & 節 & 分 析 & $\%$ & \multirow{2}{*}{$\begin{array}{l}\text { 孔䍀 } \\
\text { 柪\% }\end{array}$} & \multirow{2}{*}{$\begin{array}{l}\text { 滲透來 } \\
\text { darcy }\end{array}$} \\
\hline & $\begin{array}{r}\text { mesh } \\
100 \sim 200\end{array}$ & \multicolumn{2}{|c|}{$\begin{array}{l}\text { mesd 325mesh } \\
00 \sim 325 \text { 以 }\end{array}$} & & \\
\hline 1 & 100 & 0 & 0 & $40-4$ & $3.2 \sim 6.8$ \\
\hline II & 50 & 25 & 25 & 35 & 1.75 \\
\hline III & 25 & 25 & 50 & 45 & 1.04 \\
\hline
\end{tabular}

2) Leverett: Flow of Oil-Water Mixtures through Unconsolidated Sand, A.I.M.E.(1939), 132, 149.

3) F. G. Millers : Steady Flow of 'Two Phase Single-Component Fluids through Porous Media, Journal of Petroleum Technology, Vol. III, No. 7, (June 1951).
またF.G. Miller氏3》Kよれば 14〜28, 28〜35, 35〜。 48, 48〜65, 65〜100, 100〜200, 200〜325meshの秒を

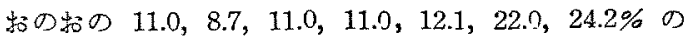

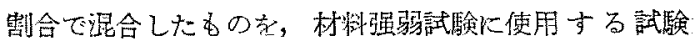

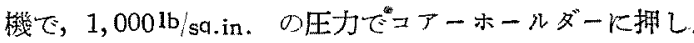

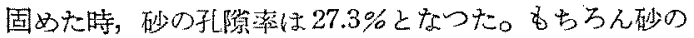

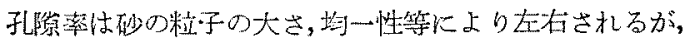

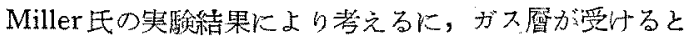
同じ程度の大さの王力で押し固かなければ，ガス曆が持

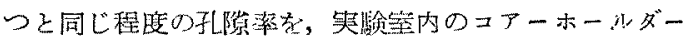
内に放いて得るこ上は国難ではないかと考えられる。良

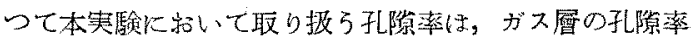
上り大きいと考元られるから，求められた相刘的透率 の值は，ガス蟹の透率より大きいと思加わ。

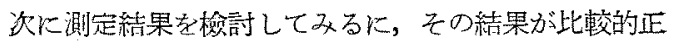
しく曲䠌上に分布するのは，乙の飽和率が50\% 65\%の

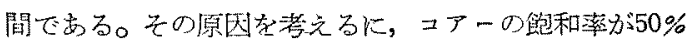

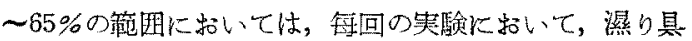

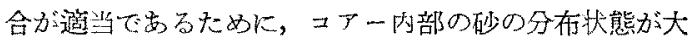

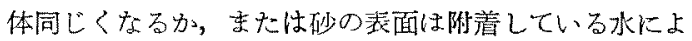

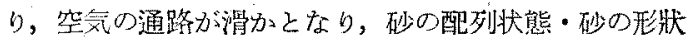
による影留が小さくなるためであると焽子れる。

50\%以下では，その求められた結果は，比較的広い籍 四に分布し，(表乹よび図には，その代表的な数值を提 げたつ飽和率か30\%以下で，その㑯间が大である。館 和率が50\%以下の場合はコアー玌陵率はほとんど同じ

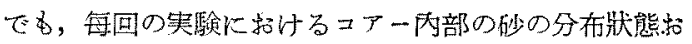

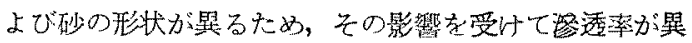

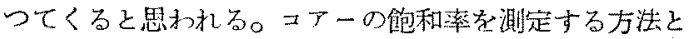

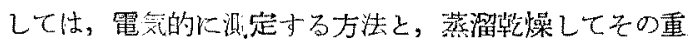
最老测定寸る方法とがあるが，砂の分布状態・砂の形狀。

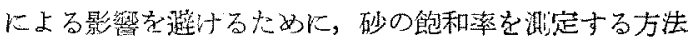
としては，笔気的に測定する方法省探用することが良い と思机れる。

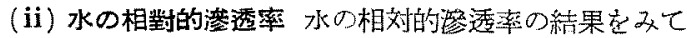

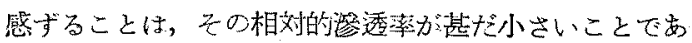
る。すなかち水の鲍和率が 95.5\%になつても，午のパー セント唀率は $1 \%$ 以下で多。笑気と水の相刘的滛透 率の実験は，砂については Muskat 氏4等が行い，䟞岩 については Botset 氏5)が行つている。 Muskat 氏等の実 験に用いら机た秒の大さは，70〜200mesh，济透率は

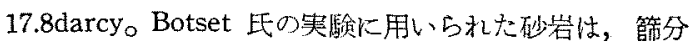

4) M. Muskat, R.D Wyckoff, H.G.Botset and M. W. Meres: Flow of Gas Liquid Mixtures through Sands, Trans. A.I.M.E.(1937), 123, 69

5) H.G.Botset : Flow of Gas-Liquid Mixtures through Consolidated Sand, 'Trans. A.I.M.E. (1940), 136, 91. 
析の結果によよれば，80〜90mesh のものが40\%程度女 り，その唀率は0.495darcyである。砂の粒子の大さが 異るのて，乙の测定結果を比較対称して，直ちに結論を

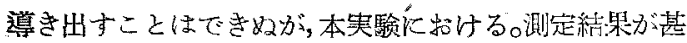
だ小さい继悉もつことに対しては，检討在加える必要が

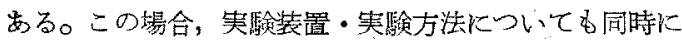
考えなければならない。

前に述べた如き方法に上り，90\%以上の飽和等至すつ

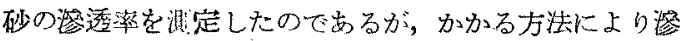

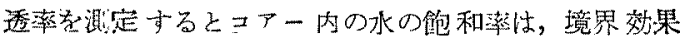
(end effect)により一㥞ではなく、ュアーの䟖端に扣い

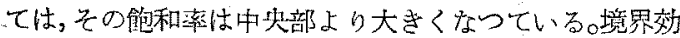
果を少なく子るため普通コアーホールダーの上流侧・下 流側に，それぞれコアーと同程度の唀率をむつ物質を

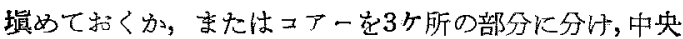

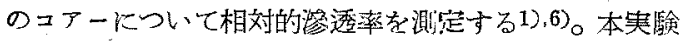
に使用した坟置る，境界效果炎小さくするよ5に裁作さ れためのて，本実駼についてるコアーホールダーの前啳 の水ールダー内にガス砂を填める予定でありたが，水を

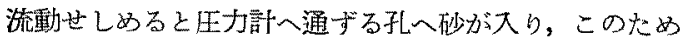

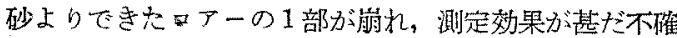
なるのとなるので,ガス砂はュアーホールダーにのみ填 め，その前後のホールダーには 48mesh の砂を填めた。 それ放境界效果のためKコアー再端の飽和率性著しく大

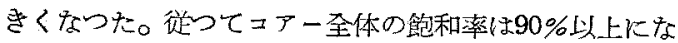
つても，中央の部分の鵨和率はそれよりる小さく，その コアーより求められた測定結果は，コアーのすべての部

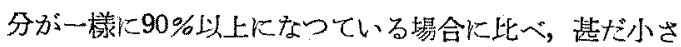

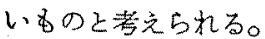

次に水と空気の相対的蓄透索を測定する場合，コアー が完全に水で飽和した時の淩透率を測定寸るこ上を必要 とする。コアーを完全炏水で飽和する方法としては，各 種の方法が用いられているが，本実で験は Leverett氏2 が用い九方法に往い，上端より真空ポンブをかけ，下端 上り水を吸い上げてみた。しかし澌定器のネジ接続の部 分より空気が大り，完全に水で飽和することに失敗した

（湘定器は水銀杜厄 $20 \mathrm{~cm}$ の压力まては，完全に気密火

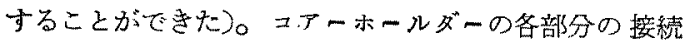
法としては，ネジで接続するるの，ボルトて接続するも のの 2 種類が古るが，ネジの部分の長ざが長い場合か， ネジが正確に切られている場合を除き，ボルト絸めする 方がよいと思われる。以上の理由により，水化上る絕対

6) T. M. Geffen, W. W. Owens, D, R. Parrish and R.M. Morse : Experimental Investigation of Factors Affecting Laboratory Relative Permeability Measurements, Journal of PetroIeum Technology, Vol. III, No.4, (April, 1951).

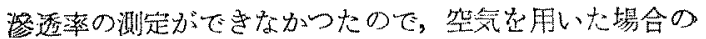

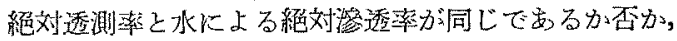
また翼つていればいかなる原因であるか子といら点につい て，充分な检訶ができからた。往つて水の相対的济透 率汃さいといら点についても，㫕全な解明が得られな sつt:

(iii) 素燒板を使用した測定器 素琴板定便用した測定 器については，I. Fatt 氏と H.Dykstra 氏7が発表した

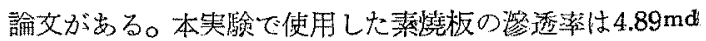

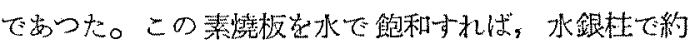
$20 \mathrm{~cm}$ の王力まで空気力゙流出することはない。する飽和

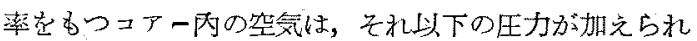
る場合には，外部に流出することがない。それ故水を流

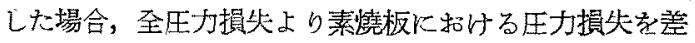

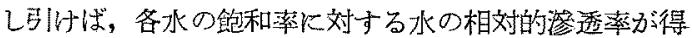
られる。この装置を用いた場合，素憢板の治透率がどの 程度の大さの时，毁も精度のよい弮駼結果が得られるか

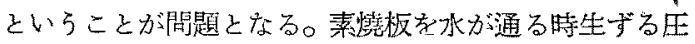

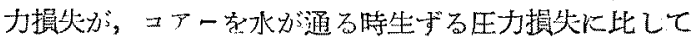

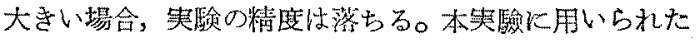

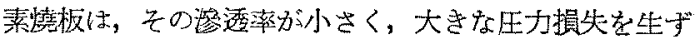

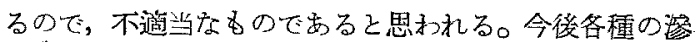

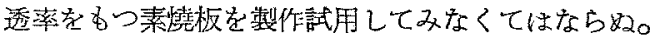

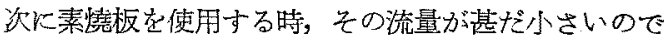
(本実験に和いては压力差加水銀杜て $17 \mathrm{~cm}$ 程度の時，そ の流量はコアーの館和率により暴るが， $0.015 \mathrm{cc} / \mathrm{sec} \sim 0$ $008 \mathrm{cc} / \mathrm{sec}$ 程度の少量であつた)その正確な評量が間題ど

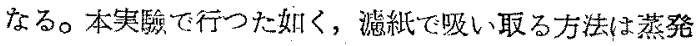
に上る損头加むるのて不正碓となるから，今後整作する 坟置では，Fatt氏が用いた如く目盛付ピペットを使用寸 る考えている。

\section{6. 結語}

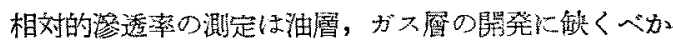
らざるるのであり，その重要性は充分に㒛識されている

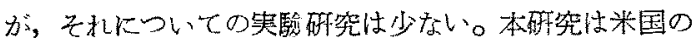

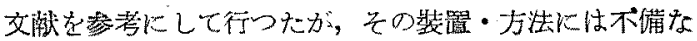

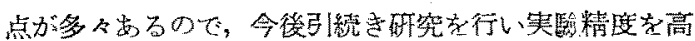

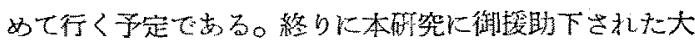

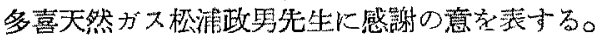

7) I. Fatt and H.Dykstra : Relative Permeability Studies, Journal of Petroleum Technology, Vol. III, No. 9 (Sepetmber 1951). 